\title{
Traumatic Transection of Pancreas at the Neck: Feasibility of Parenchymal Preserving Strategy
}

\author{
Rudra Prasad Doley ${ }^{a}$, Thakur Deen Yadav ${ }^{\mathrm{a}}$, Mandeep Kang ${ }^{\mathrm{b}}$, Ashwani Dalal ${ }^{\mathrm{c}}$, \\ Mayank Jayant ${ }^{\mathrm{c}}$, Rajeev Sharmac ${ }^{\text {, Jai Dev Wiga, }}$
}

\begin{abstract}
Background: To assess the feasibility and safety of a pancreas preserving operative technique in the management of isolated complete pancreatic neck transection following blunt abdominal trauma.

Methods: Two patients with isolated blunt fracture of the pancreatic neck underwent pancreas preserving procedure comprising of oversewing of the proximal pancreas and Roux-en-Y pancreatico jejunostomy to the distal remnant. A feeding jejunostomy tube was placed for postoperative nutritional support in these patients. Both patients received subcutaneous octreotide $300 \mu \mathrm{g} / \mathrm{day}$.
\end{abstract}

Results: Their ages ranged from 15 years to 20 years, mode of injury was bicycle handle-bar injury $(n=2)$. Both had pancreatic transection at neck in the line of superior mesenteric vessels. One had ascites. These patients had pancreas parenchyma preserving surgery - internal drainage of the left remnant in a Roux-en-Y jejunal loop. The postoperative course was uneventful in these and both are well on follow-up.

Conclusions: Pancreas preserving strategy - suture of head side of pancreas and an internal drainage of left remnant with a Roux-en-Y jejunal loop is feasible and safe and should be considered in selected cases. Substantial amount of normal pancreatic parenchyma is preserved.

Keywords: Pancreas; Pancreatic injuries; Abdominal injuries; Organ preservation; Pancreatic anastomosis

Manuscript accepted for publication February 9, 2010

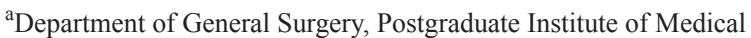
Education and Research, Chandigarh, India

${ }^{b}$ Department of Radiodiagnosis, Postgraduate Institute of Medical Education and Research, Chandigarh, India

${ }^{\mathrm{c}}$ Government Medical College, Chandigarh, India.

${ }^{\mathrm{d}}$ Corresponding author: $8 \mathrm{H}-5$, Sector-12, PGI Campus, Chandigarh

160012, India. Email: jdwsjni@hotmail.com

\section{Introduction}

Complete transection of the pancreas at pancreatic neck following blunt trauma is uncommon [1-3]. Increased morbidity and mortality result from associated vascular injuries and main pancreatic duct disruption $[4,5]$.

Management strategies described are distal pancreatectomy with splenectomy $[2,6]$, spleen preserving distal pancreatectomy, primary repair of the pancreas and main pancreatic duct [7], conservative approach [8], endoscopic stenting $[9,10]$, and pancreas parenchyma preserving surgical approach [11-13].

Distal pancreatectomy and splenectomy have been the standard of care for patients with blunt pancreatic transection. Distal pancreatectomy to the left of superior mesenteric vessels is associated with loss of significant amount of normal pancreatic parenchyma, thereby increasing the risk of pancreatic insufficiency $[14,15]$. Splenectomy is associated with a lifelong risk of infectious and hematologic morbidity $[16,17]$. Endocrine and exocrine pancreatic insufficiency, and infectious and hematological complications following distal pancreatectomy and splenectomy have prompted the pancreas and spleen preserving strategies for the management of this uncommon injury [16]. This retrospective study evaluates the feasibility and safety of pancreas parenchyma preserving option for blunt isolated pancreatic neck transection.

\section{Patients and Methods}

This is a retrospective review of two patients with isolated pancreatic neck transection managed between July 2005 to March 2009. These patients underwent emergency pancreas preserving surgery for isolated pancreatic neck fracture in the line of superior mesenteric vessels. Contrast enhanced computed tomography (CT) in these patients demonstrated the fracture (Fig. 1). An endoscopic retrograde cholangiopancreatography was not attempted in these patients.

\section{Technique}




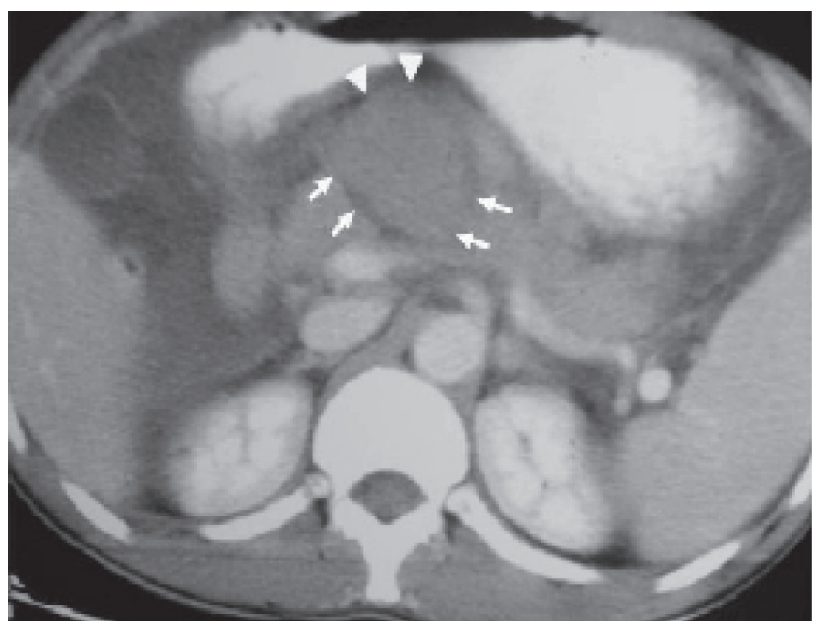

Figure 1. CECT abdomen axial image reveals complete transection between head and neck of pancreas with a rounded hypoechoic mass suggestive of hematoma separating the two fractured fragments (arrows). Note the fluid surrounding the hematoma (arrow heads).

The lesser sac was approached after ligating and dividing the gastrocolic omentum. The entire pancreas was visualized and assessed. The injury was carefully evaluated (Fig. 2) by ligation and division of remaining pancreatic attachments. The exposed superior mesenteric vein and the portal vein were carefully inspected. The proximal pancreatic head was oversewn with interrupted nonabsorbable sutures after suture ligation of the pancreatic duct. The distal end was mobilized off the superior mesentric vein, splenic vein and portal vein by ligating and dividing small posterior pancreatic vessels which were meticulously isolated. This allowed elevation of distal pancreas by approximately $2-3 \mathrm{~cm}$ for a safe pancreatico-jejunal anastomosis (Fig. 3). Reconstruc-

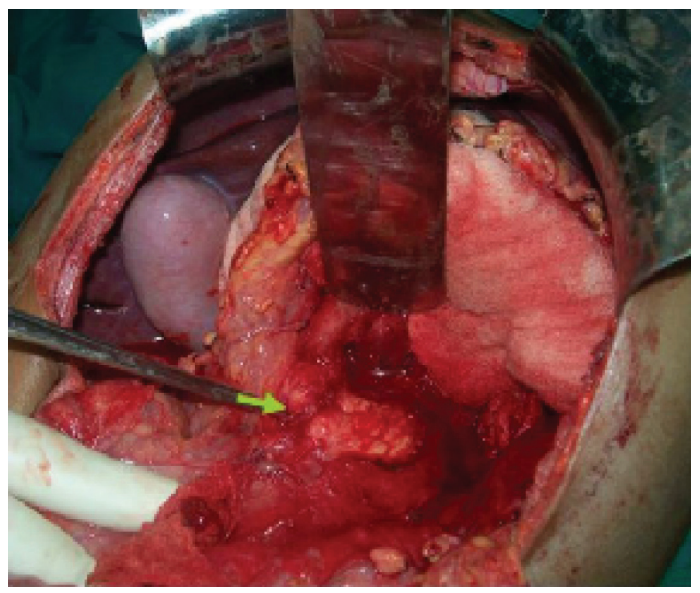

Figure 2. Intraoperative photograph shows the pancreatic fracture (arrow).

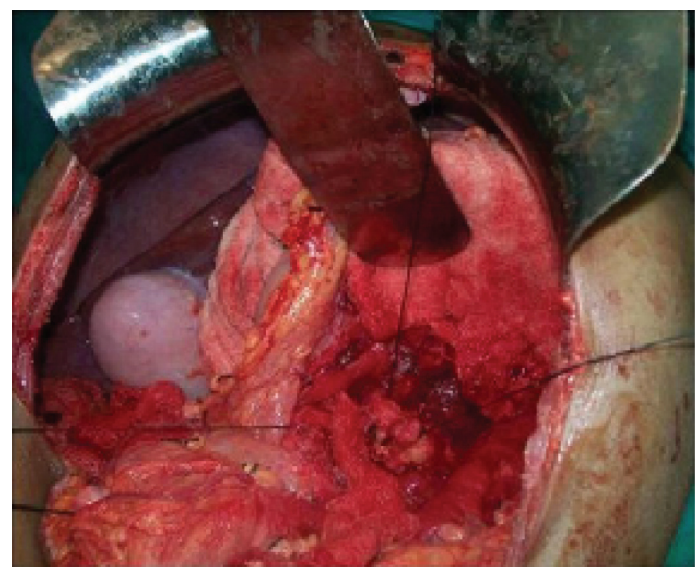

Figure 3. The distal pancreas is lifted for a distance of $2-3 \mathrm{~cm}$.

tion of the distal pancreatic remnant was accomplished by Roux-en-Y pancreaticojejunostomy (Fig. 4). An invaginated anastomosis of the distal pancreas into the gut was fashioned using fine, interrupted nonabsorbable sutures.

The operation was completed by an end-to-side jejunostomy distal to the pancreaticojejunostomy (Fig. 5). A $16 \mathrm{Fr}$ portex drain was left in place to adequately control potential leakage from both the proximal stump and the distal pancreatico-jejunostomy.

Postoperative octreotide was administered subcutaneously at a dose of $100 \mu \mathrm{g} 8$ hourly. In these patients it was continued for 7 - 10 days in an attempt to decrease the output of pancreatice juice.

\section{Results}

The clinical details of these patients are listed in Table 1 . Their ages ranged from 15 years to 20 years, and sustained

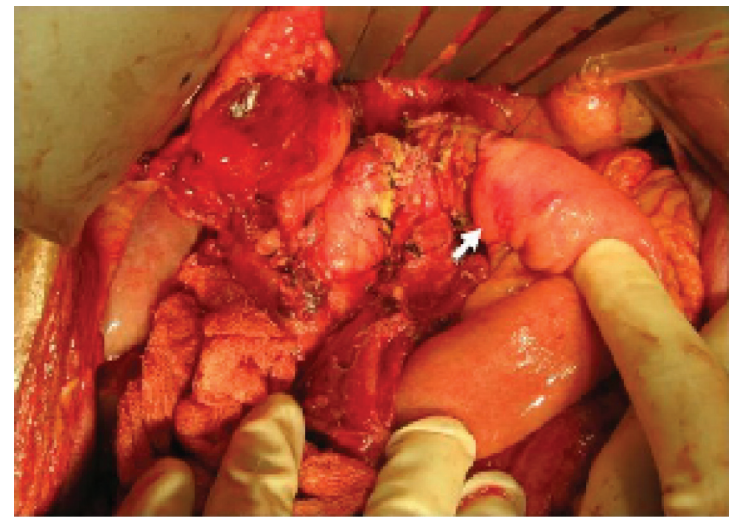

Figure 4. Anastomosis of the distal pancreas to Roux-en-Y jejunal loop. 
Table 1. Patients Demographic Characteristics

\begin{tabular}{lll}
\hline Parameter & Case 1 & Case 2 \\
\hline Age (years)/Sex & $15 /$ Male & 20/Male \\
Duration & 2 weeks & 24 hours \\
Mechanism & Bicycle handle-bar & Bicycle handle-bar \\
Clinical presentation & Ascites, dehydration, Tense abdomen & Epigastric tenderness \\
CT abdomen & Ascites, Transection neck & Transection neck \\
Operative findings & Ascites, complete transection & Hematoma complete transection \\
Operative procedure & Pancreaticojejunostomy & Pancreaticojejunostomy \\
Outcome & Recovered & Recovered \\
\hline
\end{tabular}

bicycle handle-bar injury. The clinical presentation was abdominal distention $(n=1)$, and epigastric tenderness $(n=2)$. These patients presented within 2 hours to 24 hours. CECT abdomen at admission revealed pancreatic parenchymal transection.

These patients had conservative surgery - the proximal remnant was oversewn with interrupted nonabsorbable sutures, and a Roux-en-Y pancreatico jejunostomy was performed on the left remnant.

Both these patients survived following pancreas preserving surgery and are well on follow-up ranging from 9 months to over two years.

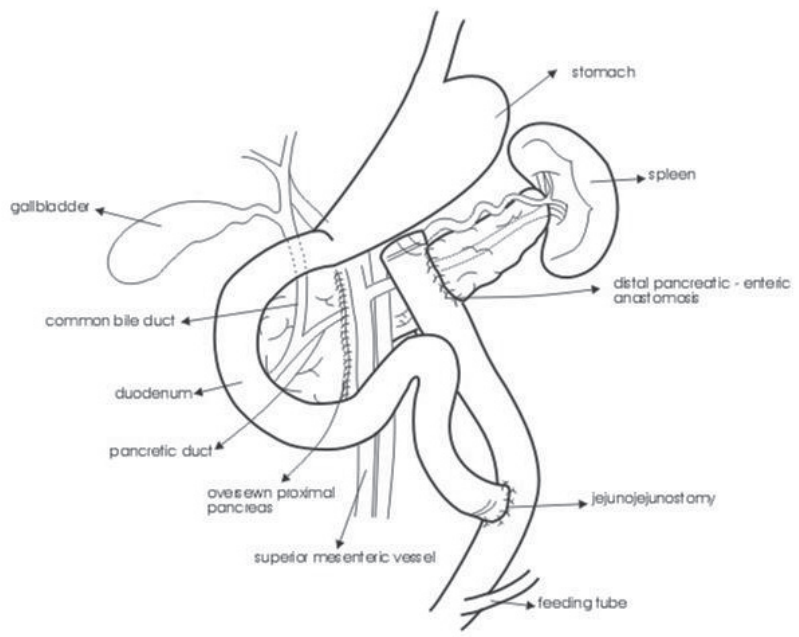

Figure 5. Line diagram describing the operative details.

\section{Discussion}

Complete pancreatic transection is rare and usually occurs in the line of superior mesenteric vessels at the neck of the gland, though it has been reported to occur in the body or tail of the pancreas $[6,18]$. In all our patients the injury was confined to the neck of the pancreas. These patients may have associated injury to superior mesenteric portal vein axis. Patients affected by associated vascular injuries are rarely described [5]. Bradley et al [19] reported this association in only 3 of 101 cases. Associated vascular injury carries a high mortaility [20] and most deaths are due to exsanguinating haemorrhage from injury to portal vein, splenic vein, or inferior vena cava [19]. Massive ascites following initial trauma is rarely reported [21]. One of our patients presented with massive ascites two weeks following a bicycle handle-bar injury. Early surgical intervention in patients with pancreatic neck transection and ductal disruption reduces pancreas related morbidity [22]. Transection at this site needs surgical intervention using either resection or internal drainage techniques depending on hemodynamic stability and associated injuries.

Various options are distal pancreatectomy with splenectomy [2, 23-25], distal pancreatectomy with splenic preservation [1], anastomosis of the duct with salvage of the whole organ [26], primary repair of the pancreas and pancreatic duct [7, 27], pancreas preserving Roux-en-Y pancreaticojejunostomy or pancreaticogastrostomy to distal segment $[12,15,28]$, and endoscopic transpapillary stent insertion $[29,30]$. Exploration and drainage alone result in fistulae, abscesses, pancreatitis, or necrosis as severe complications 


\section{$[18,31]$.}

The role of pancreatic duct stent is uncertain in patients with complete transection $[10,22,29]$, even though there are reports documenting its effectiveness in patients with duct disruption [30]. Pancreatic duct stenting may avert surgical resection when the major pancreatic duct is disrupted but not obstructed [9]. Eventually mild to severe ductal stricture results necessitating intervention [10]. The role of primary repair of the pancreas and pancreatic duct has yet to be defined [7]. Somatostatin analogue therapy may have an important role in management and reduces peripancreatic inflammation and necrosis [24]. It is reported that prophylactic use of octreotide was associated with no pancreatic sequelae [32]. Though there are reports of successful non-operative management in patients with disruption of the main pancreatic duct [33-35], others have reported development of complications resulting in long-term morbidity $[22,35]$.

Distal pancreatectomy with splenectomy is associated with loss of significant amount of normal pancreatic parenchyma $[1,15]$ and can lead to long-term pancreatic insufficiency and postsplenectomy infections.

Endocrine impairment after standard left resection is reported in $17 \%$ to $85 \%$ of patients $[36,37]$. The rationale for spleen preserving procedure is preventing postsplenectomy infectious complications. A recent study has shown that following splenectomy, patients had a significantly higher rate of infectious complications ( $28 \%$ versus $9 \%, \mathrm{p}=0.01$ ), and severe complications $(11 \%$ versus $2 \%, p=0.05)$ compared with those who had splenic preservation [38]. Other studies have also suggested that spleen preservation should be attempted in patients with benign distal pancreatic disease $[16,39]$. Preservation of the spleen may not be always technically feasible as it is more time consuming and associated with increased blood loss [38]. Another study found complication rate twice as high in the splenic preservation group as compared to splenectomy group [40].

In recent years pancreas preserving strategy has been introduced for benign or low grade malignant tumours in the neck or proximal body of the pancreas [36, 41, 42], chronic pancreatitis [43] and for blunt pancreatic neck rupture [1, $12,44]$. Pancreas preserving approach is feasible, safe and appropriate for isolated pancreatic neck transection. Different techniques for reconstruction have been adopted: jejunal anastomosis to both the proximal and distal stump or only to distal stump, or distal pancreaticogastric anastomosis [15, 37, 45]. Reconstruction of the distal pancreatic remnant accomplished with a pancreatico-jejunostomy or pancreaticogastrostomy preserves as much normal pancreas as possible. The potential risks of endocrine and exocrine insufficiency following removal of more than $50 \%$ of normal pancreas are thus prevented $[12,15,46]$. Preserving pancreatic parenchyma depends on hemodynamic stability of the patient and dense inflammatory changes in the region of the neck of the pancreas.
The procedure though technically demanding maintains the function of the pancreas. In recent studies, none of the patients had exocrine or endocrine insufficiency $[37,47,48]$. New onset diabetes is reported in less than $8 \%[45,49]$.

Hirono et al [50] analyzed the frequency of postoperative onset of diabetes mellitus and long-term changes in body weight in patients with a central pancreatectomy and compared with distal pancreatectomy group. The rate of new onset diabetes mellitus was minimal $(4.7 \%$ versus $35 \%$, p $=0.0129)$, and the body weight in distal pancreatectomy group was significantly lower than that in central pancreatectomy group at one and two years after surgery (1 year, $p$ $<0.0001,2$ years $\mathrm{p}=0.0055)$. In another study comparing middle pancreatectomy with extended left pancreatectomy, the incidence of new endocrine ( $4 \%$ vs $38 \%, p=0.0001)$ and exocrine insufficiency $(5 \%$ versus $15.6 \%, \mathrm{p}=0.039)$ were significantly higher in extended left pancreatectomy group [36]. Ocuin et al [51] have reported that extended left pancreatectomy group had a higher rate of new onset diabetes mellitus $(57 \%$ versus $11 \%, p=0.04)$ as compared to central pancreatectomy. New onset exocrine insufficiency was not significantly different between the two groups $(p=0.62)$.

Both of our patients had no morbidity following parenchyma preserving strategy. There are reports that this strategy is associated with more complications than left pancreatectomy. Ocuin et al [51] reported more complications with central pancreatectomy ( $92 \%$ versus 39\%) but there was no significant difference in major complications $(38 \%$ versus $17 \%, \mathrm{p}=0.17)$.

Zhou et al [28] reported a $37.5 \%$ morbidity rate and no mortality. The most common complication is a pancreatic leak $[52,53]$. There is a possibility of a leak from the closed cut edge of the pancreatic head, or from pancreaticojejunostomy [41, 53]. A normal soft pancreas, and a small main pancreatic duct are risk factors for pancreatic leak. There are conflicting reports regarding the pancreatic leak rate: some reporting leak rates ranging from $6 \%$ to $50 \%[28,47-49,53-$ 55], while no leak has been reported in some series [37, 44]. Rotellar et al [41] have reported that the method of pancreatic transection seems to be a decisive factor in the incidence of pancreatic head fistulas. The type of reconstruction - pancreaticogastrostomy versus pancreaticojejunostomy, and the use of a stent did not affect the rate of complications [36]. Most of the pancreatic fistulas may be managed nonoperatively [56]. The reported rates of pancreatic fistula following distal pancreatectomy are $30 \%$ to $51 \%[36,56]$. There is no significant difference in the rate of fistula formation between different stump closure methods following distal pancreatectomy and reduction of pancreatic fistulas after distal pancreatectomy remains an unsolved challenge [57].

In conclusion, the reported surgical strategy is an effective pancreas parenchyma preserving procedure with no postoperative pancreas - related morbidity or mortality. This option may be successfully applied in the emergency setting 
as a definite surgical procedure and is a promising alternative to distal pancreatectomy and splenectomy for this complex pancreatic injury.

\section{References}

1. Nikfarjam M, Rosen M, Ponsky T. Early management of traumatic pancreatic transection by spleen-preserving laparoscopic distal pancreatectomy. J Pediatr Surg 2009;44(2):455-458.

2. Leva E, Huscher C, Rode H, Fava G, Napolitano M, Maestri L, Pansini A, et al. Management of traumatic complete pancreatic fracture in a child: case report and review of literature. J Laparoendosc Adv Surg Tech A 2008;18(2):321-323.

3. Juric I, Pogorelic Z, Biocic M, Todoric D, Furlan D, Susnjar T. Management of blunt pancreatic trauma in children. Surg Today 2009;39(2):115-119.

4. Thomas H, Madanur M, Bartlett A, Marangoni G, Heaton N, Rela M. Pancreatic trauma--12-year experience from a tertiary center. Pancreas 2009;38(2):113-116.

5. Baiocchi GL, Tiberio GA, Gheza F, Gardani M, Cantu M, Portolani N, Giulini SM. Pancreatic transection from blunt trauma associated with vascular and biliary lesions: a case report. World J Gastroenterol 2008;14(30):48264829.

6. Olah A, Issekutz A, Haulik L, Makay R. Pancreatic transection from blunt abdominal trauma: early versus delayed diagnosis and surgical management. Dig Surg 2003;20(5):408-414.

7. Aucar JA, Losanoff JE. Primary repair of blunt pancreatic transection. Injury 2004;35(1):29-34.

8. Mattix KD, Tataria M, Holmes J, Kristoffersen K, Brown R, Groner J, Scaife E, et al. Pediatric pancreatic trauma: predictors of nonoperative management failure and associated outcomes. J Pediatr Surg 2007;42(2):340-344.

9. Lin BC, Fang JF, Wong YC, Liu NJ. Blunt pancreatic trauma and pseudocyst: management of major pancreatic duct injury. Injury 2007;38(5):588-593.

10. Lin BC, Liu NJ, Fang JF, Kao YC. Long-term results of endoscopic stent in the management of blunt major pancreatic duct injury. Surg Endosc 2006;20(10):15511555.

11. Buccimazza I, Thomson SR, Anderson F, Naidoo NM, Clarke DL. Isolated main pancreatic duct injuries spectrum and management. Am J Surg 2006;191(4):448452.

12. Bridoux V, Khalil H, Foulatier O, Mezghani J, Tapon E, Scotte M. [Conservative surgical treatment after complete pancreatic neck rupture]. J Chir (Paris) 2007;144(2):153-155.

13. Chinnery GE, Thomson SR, Ghimenton F, Anderson F. Pancreatico-enterostomy for isolated main pancreatic duct disruption. Injury 2008;39(1):50-56

14. Lavu H, Knuth JL, Baker MS, Shen C, Zyromski NJ, Schmidt M, Nakeeb A, et al. Middle segment pancreatectomy can be safely incorporated into a pancreatic surgeon's clinical practice. HPB (Oxford) 2008;10(6):491497.

15. Fisher JC, Kuenzler KA, Bodenstein L, Chabot JA. Central pancreatectomy with pancreaticogastrostomy in children. J Pediatr Surg 2007;42(4):740-746.

16. Lee SE, Jang JY, Lee KU, Kim SW. Clinical comparison of distal pancreatectomy with or without splenectomy. J Korean Med Sci 2008;23(6):1011-1014.

17. Kyaw MH, Holmes EM, Toolis F, Wayne B, Chalmers J, Jones IG, Campbell H. Evaluation of severe infection and survival after splenectomy. Am J Med 2006;119(3):276 e271-277.

18. Subramanian A, Feliciano DV. Pancreatic trauma revisited. Eur J Trauma Emerg Surg 2008; 34: 3-10.

19. Bradley EL, 3rd, Young PR, Jr., Chang MC, Allen JE, Baker CC, Meredith W, Reed L, et al. Diagnosis and initial management of blunt pancreatic trauma: guidelines from a multiinstitutional review. Ann Surg 1998;227(6):861-869.

20. Cirillo RL, Jr., Koniaris LG. Detecting blunt pancreatic injuries. J Gastrointest Surg 2002;6(4):587-598.

21. Takeuchi D, Kimura F, Shimizu H, Yoshidome H, Ohtsuka M, Kato A, Yoshitomi H, et al. Successful treatment for pancreatic injury presented with pancreatic ascites 2 months after a blunt abdominal trauma. Hepatogastroenterology 2008;55(86-87):1834-1837.

22. Snajdauf J, Rygl M, Kalousova J, Kucera A, Petru O, Pycha K, Mixa V, et al. Surgical management of major pancreatic injury in children. Eur J Pediatr Surg 2007;17(5):317-321.

23. Ahmad I, Branicki FJ, Ramadhan K, El-Ashaal Y, AbuZidan FM. Pancreatic injuries in the United Arab Emirates. Scand J Surg 2008;97(3):243-247.

24. Lochan R, Sen G, Barrett AM, Scott J, Charnley RM. Management strategies in isolated pancreatic trauma. J Hepatobiliary Pancreat Surg 2009;16(2):189-196.

25. Li JC, Ng SS, Teoh AY, Leung KL. Laparoscopic spleenpreserving pancreatectomy for traumatic pancreatic transection: a case report. Surg Laparosc Endosc Percu$\tan$ Tech 2006;16(1):41-43.

26. Wirth H, Lochbuhler H, Schaupp W, Brands W, Manegold BC. [Organ preservation by reconstruction of Wirsung's duct in complete pancreas rupture]. Langenbecks Arch Chir 1991;376(4):228-231.

27. La Greca G, Castello G, Barbagallo F, Conti P, Latteri S, Randazzo V, Gresta S, et al. [Pancreatic trauma: a case report]. Chir Ital 2006;58(1):93-99.

28. Zhou J, Dong M, Kong F, Li Y, Tian Y. Central pancreatectomy for benign tumors of the neck and body of the pancreas: report of eight cases. J Surg Oncol 
2009;100(3):273-276.

29. Kim HS, Lee DK, Kim W, Baik SK, Kwon SO, Park JW, Cheon N, Rhoe BS. The role of endoscopic retrograde pancreatigraphy for traumatic pancreatic duct injury. Korean J Gastrointest Endosc 2001; 22: 88-95.

30. Canty TG, Sr., Weinman D. Management of major pancreatic duct injuries in children. J Trauma 2001;50(6):1001-1007.

31. Degiannis E, Glapa M, Loukogeorgakis SP, Smith MD. Management of pancreatic trauma. Injury 2008;39(1):2129.

32. Amirata E, Livingston DH, Elcavage J. Octreotide acetate decreases pancreatic complications after pancreatic trauma. Am J Surg 1994;168(4):345-347.

33. Shirai Y, Tsukada K, Yamadera Y, Ohtani T, Muto T, Hatakeyama K. Blunt pancreatic trauma with main pancreatic duct disruption managed successfully with total parenteral nutrition: report of a case. Surg Today 1995;25(1):76-78.

34. Jacombs AS, Wines M, Holland AJ, Ross FI, Shun A, Cass DT. Pancreatic trauma in children. J Pediatr Surg 2004;39(1):96-99.

35. Wales PW, Shuckett B, Kim PC. Long-term outcome after nonoperative management of complete traumatic pancreatic transection in children. J Pediatr Surg 2001;36(5):823-827.

36. Crippa S, Bassi C, Warshaw AL, Falconi M, Partelli S, Thayer SP, Pederzoli P, et al. Middle pancreatectomy: indications, short- and long-term operative outcomes. Ann Surg 2007;246(1):69-76.

37. Goldstein MJ, Toman J, Chabot JA. Pancreaticogastrostomy: a novel application after central pancreatectomy. J Am Coll Surg 2004;198(6):871-876.

38. Shoup M, Brennan MF, McWhite K, Leung DH, Klimstra D, Conlon KC. The value of splenic preservation with distal pancreatectomy. Arch Surg 2002;137(2):164168.

39. Lee SY, Goh BK, Tan YM, Chung YF, Cheow PC, Chow PK, Wong WK, et al. Spleen-preserving distal pancreatectomy. Singapore Med J 2008;49(11):883-885.

40. Benoist S, Dugue L, Sauvanet A, Valverde A, Mauvais $\mathrm{F}$, Paye F, Farges $\mathrm{O}$, et al. Is there a role of preservation of the spleen in distal pancreatectomy? J Am Coll Surg 1999;188(3):255-260.

41. Rotellar F, Pardo F, Montiel C, Benito A, Regueira FM, Poveda I, Marti-Cruchaga P, et al. Totally laparoscopic Roux-en-Y duct-to-mucosa pancreaticojejunostomy after middle pancreatectomy: a consecutive nine-case series at a single institution. Ann Surg 2008;247(6):938944.

42. Brown KM, Shoup M, Abodeely A, Hodul P, Brems JJ, Aranha GV. Central pancreatectomy for benign pancreatic lesions. HPB (Oxford) 2006;8(2):142-147.

43. Muller MW, Friess H, Kleeff J, Hinz U, Wente MN,
Paramythiotis D, Berberat PO, et al. Middle segmental pancreatic resection: An option to treat benign pancreatic body lesions. Ann Surg 2006;244(6):909-918; discussion 918-920.

44. Johnson MA, Rajendran S, Balachandar TG, Kannan DG, Jeswanth S, Ravichandran P, Surendran R. Central pancreatectomy for benign pancreatic pathology/trauma: is it a reasonable pancreas-preserving conservative surgical strategy alternative to standard major pancreatic resection? ANZ J Surg 2006;76(11):987-995.

45. Efron DT, Lillemoe KD, Cameron JL, Yeo CJ. Central pancreatectomy with pancreaticogastrostomy for benign pancreatic pathology. J Gastrointest Surg 2004;8(5):532538.

46. Zingales F, Fabris G, Ronconi AM, Pivetta E, Bozza F, Menegazzo M, Vittadello F, et al. [Pancreatic neck rupture: report of a clinical case]. Chir Ital 2003;55(1):109112 .

47. Sa Cunha A, Rault A, Beau C, Collet D, Masson B. Laparoscopic central pancreatectomy: single institution experience of 6 patients. Surgery 2007;142(3):405-409.

48. Iacono C, Bortolasi L, Serio G. Indications and technique of central pancreatectomy-early and late results. Langenbecks Arch Surg 2005;390(3):266-271.

49. Allendorf JD, Schrope BA, Lauerman MH, Inabnet WB, Chabot JA. Postoperative glycemic control after central pancreatectomy for mid-gland lesions. World J Surg 2007;31(1):164-168; discussion 169-170.

50. Hirono S, Tani M, Kawai M, Ina S, Nishioka R, Miyazawa M, Shimizu A, et al. A central pancreatectomy for benign or low-grade malignant neoplasms. J Gastrointest Surg 2009;13(9):1659-1665.

51. Ocuin LM, Sarmiento JM, Staley CA, Galloway JR, Johnson CD, Wood WC, Kooby DA. Comparison of central and extended left pancreatectomy for lesions of the pancreatic neck. Ann Surg Oncol 2008;15(8):20962103.

52. Kurohi T, Tajima Y, Tsuneoka N, Mishima T, Adachi T, Kitasato A, Kanematsu T. A jejunal wall-covering method following central pancreatectomy for prevention of a pancreatic fistula: a novel technique. Hepatogastroenterology 2008;55(85):1478-1479.

53. Christein JD, Smoot RL, Farnell MB. Central pancreatectomy: a technique for the resection of pancreatic neck lesions. Arch Surg 2006;141(3):293-299.

54. Bassi C. Middle segment pancreatectomy: a useful tool in the management of pancreatic neoplasms. J Gastrointest Surg 2007;11(4):421-424.

55. Suzuki S, Kaji S, Koike N, Harada N, Tanaka S, Hayashi T, Suzuki M, et al. Pancreaticojejunostomy of duct to mucosa anastomosis can be performed more safely without than with a stenting tube. Am J Surg 2009;198(1):5154.

56. Goh BK, Tan YM, Chung YF, Cheow PC, Ong HS, 
Chan WH, Chow PK, et al. Critical appraisal of 232 consecutive distal pancreatectomies with emphasis on risk factors, outcome, and management of the postoperative pancreatic fistula: a 21-year experience at a single institution. Arch Surg 2008;143(10):956-965.
57. Ferrone CR, Warshaw AL, Rattner DW, Berger D, Zheng H, Rawal B, Rodriquez R, Thayer SP, Fernandez - del Castillo C. Pancreatic fistula rates after 462 distal pancreatectomies: staplers do not decrease fistula rates. J Gastrointest Surg 2008;12:1691-71. 